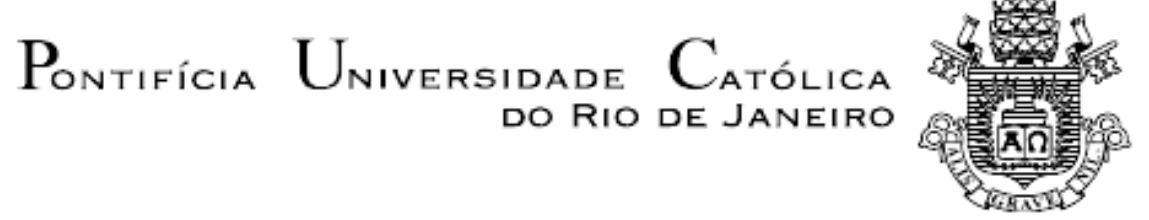

Isabelita Maria Crosariol

Tese apresentada ao Programa de Pós-graduação em Literatura, Cultura e Contemporaneidade da PUC-Rio, como parte dos requisitos para obtenção do título de Doutor em Literatura, Cultura e Contemporaneidade.

Orientador: Prof. Alexandre Montaury Baptista Coutinho 


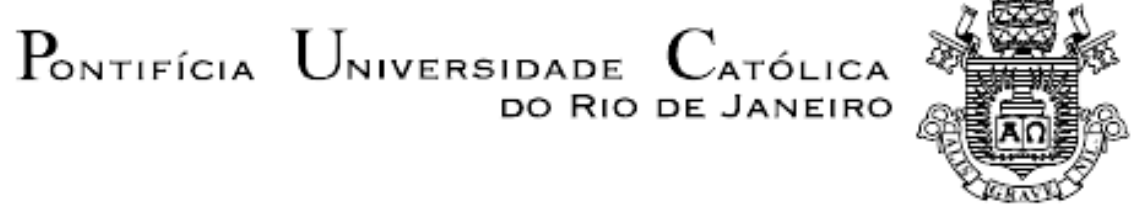

Isabelita Maria Crosariol

\title{
O LEGADO DE PRÓSPERO: UMA INVESTIGAÇÃO DO PROJETO NARRATIVO DE RUY DUARTE DE CARVALHO
}

\begin{abstract}
Defesa de Tese apresentada como requisito parcial para obtenção do grau de Doutor pelo Programa de Pós-Graduação em Literatura, Cultura e Contemporaneidade do Departamento de Letras do Centro de Teologia e Ciências Humanas da PUC-Rio. Aprovada pela Comissão Examinadora abaixo assinada.
\end{abstract}

Prof. Alexandre Montaury Baptista Coutinho Orientador Departamento de Letras - PUC-Rio

Profa. Eneida Leal Cunha Departamento de Letras - PUC-Rio

Prof. Paulo Roberto Tonani do Patrocínio Departamento de Letras - PUC-Rio - Pesquisador visitante

Prof. Emerson da Cruz Inácio USP

Prof. Silvio Renato Jorge UFF

Profa. Denise Berruezo Portinari Coordenadora Setorial do Centro de Teologia e Ciências Humanas - PUC-Rio

Rio de Janeiro, 15 de abril de 2013. 
Todos os direitos reservados. É proibida a reprodução total ou parcial do trabalho sem autorização da universidade, da autora e do orientador.

\section{Isabelita Maria Crosariol}

Graduou-se em Letras pela UNITAU em 2003, mesma instituição na qual cursou Pós-Graduação Lato Sensu em Literatura nos anos de 2005 e 2006. Em 2009, concluiu o Mestrado em Letras - Estudos da Literatura pela PUCRio, tendo, ao longo desses anos, desenvolvido pesquisas ligadas sobretudo às Literaturas Africanas de Língua Portuguesa.

Ficha Catalográfica

Crosariol, Isabelita Maria

O legado de próspero : uma investigação do projeto narrativo de Ruy Duarte de Carvalho / Isabelita Maria Crosariol ; orientador: Alexandre Montaury Baptista Coutinho. - 2013.

180 f. ; $30 \mathrm{~cm}$

Tese (doutorado)-Pontifícia Universidade Católica do Rio de Janeiro, Departamento de Letras, 2013.

Inclui bibliografia

1. Letras - Teses. 2. Ruy Duarte de Carvalho. 3. Literatura contemporânea. 4. Próspero e Caliban. 5. Angola. 6. Teoria pós-colonial. I. Coutinho, Alexandre Moutaury Baptista. II. Pontifícia Universidade Católica do Rio de Janeiro. Departamento de Letras. III. Título. 
À minha amada filha felina Pretinha

Você, assim como eu, percebe os indivíduos para além de suas cores, "raças", linguagens e espécies. 


\section{Agradecimentos}

Ao Professor Alexandre Montaury, orientador desta tese, responsável, já no início do meu Mestrado, por estimular meu interesse pela obra de Ruy Duarte de Carvalho e que acompanhou, desde então, as minhas pesquisas acerca desse autor angolano e de sua criação literária.

À Professora Eneida Leal Cunha, cuja disciplina ministrada na PUC-Rio em 2009.1 contribuiu muito para meu amadurecimento crítico. Agradeço também pelos apontamentos feitos durante o Exame de Qualificação, que ajudaram a transformar esta tese no que ela é hoje.

Ao Professor Paulo Roberto Tonani do Patrocínio, da PUC-Rio, por ter gentilmente aceitado fazer parte da banca de minha tese de Doutorado, bem como pela leitura atenciosa de meu trabalho.

Ao Professor Ronaldo Menegaz, que embora sido meu professor apenas no Mestrado e não lecione mais na PUC-Rio, marcou minha vida como exemplo de sabedoria e de virtude.

Ao Professor Silvio Renato Jorge, da UFF, que tive a oportunidade de conhecer em meu Exame de Qualificação. Agradeço a leitura atenciosa que fez de meu texto na ocasião, bem como as indicações de leitura. Foram de grande valia.

Ao Professor Emerson da Cruz Inácio, cuja disciplina "Literatura Comparada e Estudos Culturais", oferecida na USP, em 2009, colocou-me em contato com textos teóricos bastante densos, porém explicados de uma forma bastante clara, crítica e repleta de exemplos extraídos de obras literárias de diversos países.

Ao Professor Helder Garmes, também da USP; sua disciplina "Literatura e mestiçagem nos países de língua portuguesa", ministrada em 2010, possibilitou o aprofundamento de minhas reflexões sobre a mestiçagem em Angola. 
Ao Conselho Nacional de Desenvolvimento Científico e Tecnológico, pelo apoio dado a esta pesquisa.

Às amizades que se mantiveram para além do meio acadêmico. Da PUC-Rio, destaco o nome de José Carlos Vieira da Fraga (o Carlos Peicy); da USP, o nome da Erika Horigoshi. Ambos companheiros de diálogos, de discussões teóricas, de viagens, de congressos. Nossa amizade supera as distâncias, é desmedida.

À Helenice Cunha, Waltecy Alves, Cybele Regina, Jorge Otinta, pessoas de coração bom que acompanharam minha jornada acadêmica.

À querida amiga Elaine, que acompanhou de perto a elaboração de minha tese e que me ajudou a organizar, em arquivos distintos, os fichamentos dos livros que eu havia lido.

Aos meus alunos de todos os tempos. É com vocês que o conhecimento faz sentido.

À minha mãe, Bernardete Gonçalves Mendes, que, mesmo sem fazer parte do meio acadêmico, mostrou-se sempre preocupada com o andamento da minha tese e me apoiou em minhas escolhas.

Ao meu pai, Lucélio Vitório Crosariol, pelo incentivo sempre dado para que eu concluísse mais esta etapa de minha jornada; por estar perto, mesmo não morando em Taubaté.

À linda Lavínia, afilhada e sobrinha mais querida do mundo, por sempre alegrar a minha existência e deixar a minha vida mais leve.

A Ruy Duarte de Carvalho, por ter existido, por ter deixado seu legado. Aprendi muito lendo seus textos! Obrigada. 


\section{Resumo}

Crosariol, Isabelita Maria; Coutinho, Alexandre Montaury Baptista. O legado de Próspero: Uma investigação do projeto narrativo de Ruy Duarte de Carvalho. Rio de Janeiro, 2013. 180 p. Tese de Doutorado. Departamento de Letras, Pontifícia Universidade Católica do Rio de Janeiro.

"O legado de Próspero: uma investigação do projeto narrativo de Ruy Duarte de Carvalho" parte do estudo da peça de William Shakespeare intitulada $A$ tempestade para verificar, segundo uma perspectiva pós-colonial, a abordagem da colonização nas narrativas do escritor angolano Ruy Duarte de Carvalho. Publicadas após a independência de Angola, nelas a experiência da colonização não se mostra como um processo plenamente findado, visto que suas marcas ecoam no presente. Assim, Próspero e Caliban (personagens da peça shakespeariana considerados, a partir da década de 1950, como respectivos símbolos do colonizador e do colonizado) e a simbologia da tempestade são aqui teoricamente retomados na tentativa de elucidar os novos impasses vivenciados após a descolonização angolana. Para se estabelecer a aproximação entre a peça de William Shakespeare e as narrativas de Ruy Duarte de Carvalho, levou-se em conta o diálogo teórico proposto pelo autor angolano ao nomear sua trilogia como "Os Filhos de Próspero" (aludindo ao processo de mestiçagem física e cultural advindo da colonização), bem como a recorrência temática da tempestade em sua criação artística. Nesta Tese, além das narrativas que compõem a trilogia "Os filhos de Próspero" - Os papeis do inglês (2000), As paisagens propícias (2005) e A terceira metade (2009) -, são também analisadas as obras Como se o mundo não tivesse leste (1977), Vou lá visitar pastores (1999) e Desmedida (2006).

\section{Palavras-chave}

Ruy Duarte de Carvalho; Literatura Contemporânea; Próspero e Caliban; Angola; Teoria pós-colonial. 


\section{Abstract}

Crosariol, Isabelita Maria; Coutinho, Alexandre Montaury Baptista (Advisor). Prosper's Legacy: an investigation on Ruy Duarte de Carvalho's narrative Project. Rio de Janeiro, 2013. 180 p. Doctor thesis. Departamento de Letras, Pontifícia Universidade Católica do Rio de Janeiro.

'Prosper's legacy: an investigation Ruy Duarte de Carvalhos's narrative Project" analyses, upon a post colonial point of view, William Shakespeare's play entitled The Tempest, to verify the colonization approach in the narratives of the Angolan writer Ruy Duarte de Carvalho. Published after the independence of Angola, these works don't show the colonization experience as a fully complete process since its traces reverberate in the present time. Thus, Prospero and Caliban (Shakespearean characters considered after the 1950s as respective symbols of the colonizer and the colonized) and the tempest symbology are theoretically discussed, in this research, to elucidate the new obstacles experienced after the Angolan decolonization. To establish the approach between Shakespeare's play and Ruy Duarte de Carvalhos's narratives, the theoretical dialog proposed by the Angolan author naming his trilogy as "Os filhos de Próspero" (referring to the physical and cultural miscegenation process as a result of the colonization) was considered as well as the tempest thematic recurrence in his artistic creation. In this thesis, besides the narrations that set "Os filhos de Próspero" - Os papeis do inglês (2000), As paisagens propícias (2005) e A terceira metade (2009) -, Como se o mundo não tivesse leste (1977), Vou lá visitar pastores (1999) e Desmedida (2006) are also analyzed.

\section{Key-words}

Ruy Duarte de Carvalho; Contemporary Literature; Prosper and Caliban; Angola; Post-Colonial theory. 


\section{Sumário}

$\begin{array}{ll}\text { Introdução } & 11\end{array}$

$\begin{array}{lr}1 \text { Principia a tempestade } & 20\end{array}$

1.1 Prósperos calibanizados e calibans prosperizados 26

1.3 Da necessidade de uma nova tempestade em Angola 40

2 A tempestade chega ao sul angolano $\quad 50$

2.1 Várias versões para a chuva $\quad 54$

$\begin{array}{ll}2.2 \text { Os pastores, a chuva, os bois } & 72\end{array}$

3 “Os filhos de Próspero” 93

3.1 Um inglês em terra de calibans 98

3.2 Por uma epistemologia mestiça 117

3.3 A terceira margem de Angola 133

4 Uma Angola desmedida 149

4.1 Os sertões revisitados 151

$\begin{array}{ll}\text { Considerações finais } & 165\end{array}$

$\begin{array}{lc}\text { Referências bibliográficas } & 168\end{array}$ 
Um homem não é mais que este volume em que progride, esta fatal grandeza em que se inscreve, esta ausência de idade em que transita, esta força de deus a que se entrega. A chuva é o seu gesto, a sua voz a voz da tempestade, e é já sua também a sombra da montanha, a forma do granito, o peso deste sol, a força deste vento. E o crime desta ausência, a maldição gratuita deste pó, a crueza incisiva desta luz, este temor passivo de extinção.

Ruy Duarte de Carvalho 